\title{
Child Abuse and Low Fertility Theoretical Perspectives
}

\author{
MIKKO A. SALO
}

Assistant

Department of Economics and Social Policy

University of Turku

\section{Introduction}

Simultaneously with a significant economic growth, average family size and infant mortality have dramatically decreased during the last decades in the more developed countries. From a pre-transitionary level of about 30 or 40 per 1000 , crude birth rates have fallen in these countries to as low as from 15 to 17 per cent per 1000, approximately. Up to and including the eighteenth century, fertility was about four to five children per woman, whereas now, the estimated lifetime fertility rates of cohorts between 1930 and 1940 are around 1.5 children per woman (see Calot \& Hecht 1978). As late as in the 1870s the infant mortality rate in European countries varied from 100 in Norway to nearly 300 (per 1000 live births) in Southern Germany. At the turn of the century, the infant mortality rate in the eastern part of the United States was about 125 per 1000 (see U.N. 1975, 123-125). During the previous half of this century, however, infant mortality decreased by $75-80$ per cent in most industrialized countries. In the Scandinavian countries the rates are around 10 per 1000 live births now (see Statistical . . 1981, 420).

These interrelated developments may lead one to assume that the quality of life of the entire population of children and adolescents in these countries has improved to such a degree that the miserable conditions of the 19th century - well-known from the works of Charles Dickens and citations from royal commissioners' reports included in Das Kapital by Karl Marx - have been eradicated. Since the early 1960s, however, an increasing number of studies have shown that the neglect, abuse and maltreatment of children have not disappeared. In fact, the indications of the increasing problems of children and young persons in the modern welfare societies seem to be numerous:

(i) A conference on the child and the adolescent in society, recently convened by the World Health Organization Regional Office for Europe, has reported that industrialization and changes in developed countries have created conditions which favor the emergence of new problems of children of school age (WHO 1979). There 
is an evident change away from acute physical diseases towards chronic diseases and psychosocial problems.

Juvenile delinquency is increasing in most European countries. The abuse of substances, including tobacco, alcohol, cannabis and »hard» drugs is widespread among children and adolescents. There are many problems associated with the stresses of schooling. At school entry, school phobia is common. At older ages antipathy, truancy and early school-leaving are major problems. In extreme cases, the problems of schooling are contributing to suicidical behavior (ibid., 22 ). Also the number of children who have prematurely left their homes and schools to get away from parental neglect or abuse is large in some developed countries. It is estimated that there are more than one million runaway children in the United States each year (Densen-Gerber \& Hutchinson 1978).

The incidence of veneral diseases has dramatically risen (WHO 1979, 16-17). The growing number of adolescent pregnancies, without a simultaneous increase in the rates of induced abortion in adolescents, has resulted in a rapid increase in the number of births to teenage girls in most European countries. In the United States, about 17,000 babies were born to mothers under 14 years of age in 1976 (DensenGerber \& Hutchinson 1978, 323).

The conference states also that mortality rates for children of school age in fully industrialized countries have not decreased during the last few years. In fact, in several 'over-developed' countries they have risen due to increases in the number of violent deaths (WHO 1979, 12). Accidents and suicides are the leading causes of mortality in children and young people. Accidents, alone, account for one-half or more of all deaths in the age-group 5-18 years. During the 1960 s the suicide rates among teenagers over 15 years increased significantly. This tendency has continued in the 1970s (ibid., 20).

(ii) However, not only the consequences of environmental hazards are manifest in the developed countries. There coexists violence in the home, as well. It has been argued by M. D. Freeman that more violence takes place »within the privacy of the immured family» than in the outside world (Freeman 1979, 1). He continues subsequently (ibid., 11):

»A girl of four 'roasted' in front of an open fire by her father because she could not remember what she had eaten for her school lunch . . . a boy of 20 months whose feet were deliberately burnt by his mother with a lighted cigarette end, ... . a six-week old baby girl whose leg was bent backwards until it snapped and who also had severe head injuries, . . . a girl of eight months who died of brain damage caused by her mother's violent shaking of her, are just four reported instances of child abuse in Britain today.»

Physical assaults upon children by parents or other caretaking adults are phenomena which continuously occur in all developed countries. It is estimated that between 3,500 and 4,500 children suffer non-accidental injury at the hands of their parents each year in Britain. Between 250 and 450 children die as a result of these damages (ibid., 20). In West Germany, the average number of men and women who 
were sentenced for endangering the physical or mental well-being of children was in the beginning of the 1970 s about 4,500 per year. The mean number of their victims was about 6,500 per year - most of them were 3 years of age or younger (Oliver 1978). Usually the incidence of child abuse is much higher than indicated by official statistics. In Finland, 144 cases of maltreatment of children were registered by the child welfare authorities in $1978 .{ }^{1} \mathrm{~A}$ contemporary Gallup-survey, however, in that year suggests that there actually were about 50,000 children who had suffered physical injury caused deliberately or in a burst of anger by an adult person. Approximately, in 200-300 cases the injuries were serious (see Vuoristo 1979). The estimates of the rate of child abuse in the United States vary from less than one child in 10,000 to four children in 100 (see Oliver 1978, Light 1973, Kempe \& Kempe 1978, 20-21). In Florida, the 'hot-line' telephone system receives yearly about 20,000 calls from people who are worried enough to report a case of child abuse in their neighborhood (Oliver 1978, 106-107). The total population of Florida is about 5 million.

The use of physical modes of correction is widespread among parents in the developed countries even today. It is estimated that between 84 and 97 per cent of all parents in the United States and England use physical punishment at some point in their child's life (Jacobs 1978). Approximately 60 per cent of children at 1 year of age and 97 per cent at 4 years are subject to physical punishment in Britain (Newson \& Newson 1965). In West Germany, 80 per cent of parents beat their children. In 1978, more than 44 per cent of adult population of Finland considered physical punishment of children necessary in order to maintain discipline (Vuoristo 1979). In Sweden such attitudes seem to be more infrequent (see Korpilahti 1981). Nevertheless, as is mentioned by J. E. Oliver, win all these cultures, canes can be used in cold blood - a practice which surely indicates parental incompetence, ineffectuality and weakness, as well as unkindness.» (Oliver 1978, 98).

(iii) There is still the third dimension of the maltreatment of children in modern societies: the use of children for the purposes of prostitution, sexual exhibition, the production of pornographic materials and other criminal or immoral activities. It has been reported by Judianne Jensen-Gerber and S. F. Hutchinson (1978) that there are probably over two million children involved in child prostitution in the United States. They are employed and rotated around the country by technologically advanced organizations which utilize computers to meet customers' demands in the most efficient way. The authors estimate also that the exploitation of children in the production of sexually explicit films and magazines is a billiondollar industry in the country.

\section{The causes of child abuse}

The question is raised in this peper as to whether there is an association between the simultaneous appearances of child abuse and low fertility in the welfare

\footnotetext{
1 Official Statistics of Finland 1980, XXI B: 20, 76.
} 
societies. It is not, of course, justified to assume that neglect and maltreatment of children are new phenomena in the history of mankind - neither do we believe in their non-existence in the developing countries (c.f., Kempe \& Kempe 1978, Oliver 1978)..$^{2}$ It seems, however, unlikely that the causes or the multidimensional causal structures of child abuse could be essentially the same in different types of societies; although its manifestations are invariable, in this respect. Therefore, the question is, what are the underlying factors which probably maintain the appearance of child neglect and abuse in the low-fertility countries? What appears curious is the fact that simultaneously with high rates of child abuse the levels of fertility are very low in the developed countries. People have less children than ever before; nevertheless, it seems that they do not love them. Apparently, such a state of affairs would contradict common sense which says that the more scarcer a thing is the more greatly it tends to be valued. This paradox leads one to ask whether there exists a connection between child abuse and prevalent efforts to limit family size very effectively.

For the purposes of this paper the almost classical definition of child abuse presented by Henry Kempe (1962) will be used. It includes all the situations

"... in which a child is suffering from serious injury inflicted upon him by other than accidental means; is suffering harm by reason of neglect, malnutrition, or sexual abuse; is going without necessary and basic physical care; or is growing up under conditions which threaten his physical and emotional survival. $»^{3}$

Let us consider some theoretical studies which have explored causes of child abuse.

\section{A social psychological model by Gelles}

Literature on the medical and psychological aspects of the problem of child abuse is extensive. ${ }^{4}$ Many authors have pointed to the presence of psychoses among parents who have maltreated their children. In addition to the psychopathological explanations, a number of psychodynamic models and models which are based on personality theories have been introduced (see e.g., Freeman 1979, $21-27$ and Henry 1978). It has been emphasized that in many cases the abusing parents have themselves been subject to physical or emotional neglect as children.

The psychological approach, however, has raised criticism among some authors. John J. Spinetta and David Rigler (1972) have concluded that many psychological studies on child abuse "start and end as broad studies with relatively untested common-sense assumptions». The reason is that most of them are retrospective. Spinetta and Rigler have also pointed to an unsatisfactory use of sampling techniques applied to gather the data.

\footnotetext{
2 See also The History of Childhood (1974).

${ }^{3}$ Cf. Abrams 1979.

${ }^{4}$ For a review see Spinetta \& Rigler (1972) or Lystad (1975).
} 
Richard J. Gelles has contributed to this discussion with some additional critical comments (Gelles 1973). He argues that most of the psycho-pathological models are inconsistent and contradictory. "Some authors contradict themselves by first stating that the abusing parent is a psychopath and then stating that the child abuser is no different from the rest of society», Gelles writes (ibid., 613-614). Furthermore, there seems to be disagreement among the representatives of the psychopathological school on the personality traits that characterize the pathology. Gelles continues (ibid., 614): »Of nineteen traits listed by the authors, there was agreement by two or more authors on only four traits. Each remaining trait was mentioned by only a single author.»

Gelles feels that a more fruitful approach of focusing on sociological and contextual variables associated with abuse is necessary. He introduces »a social psychological model of causes of child abuse» (ibid., 619).

The model assumes that stress and frustration in the family are factors of major importance. Child abuse is considered be Gelles as an adaptation to stress. The situational stress depends on relations between parents. Simultaneously, as Gelles explicates, there are several structural and child-produced stress generating factors involved. The causal sub-structure constructed from these elements - and associated with socialization, experiences of parents and their social position variables - have a determining influence upon the immediate precipitating situations, with child abuse as a possible result. The psychopathic states are not totally excluded by Gelles. They are present in his model as intervening - although not necessary - variables in his explanation.

\section{A structural model by Gil}

There is another well-known theory of child abuse which considers stress and frustration in the family as a decisive factor. It is developed by David G. Gil (1975). Gil states that three levels of manifestation of child abuse may be distinguished. Firstly, »the most familiar one is abusive conditions in the home, and abusive interaction between children and their caretakers» (ibid., 347). Secondly, there is the institutional level which includes »such settings as day care centers, schools, courts, child care agencies, welfare departments and correctional and other residential child care settings» (ibid., 347). And lastly, the third level is the societal one: »On this level originate social policies which sanction or cause severe deficits between the actual circumstances of children and conditions needed for their optimal development» (ibid., 348). The importance of the third level is emphasized by Gil. He writes as follows (ibid., 349):

"... Of the three levels of child abuse sketched here, the societal level is certainly most severe. For what happens at this level determines not only how children fare on the institutional level, but also, by way of complex interactions, how they fare in their own homes.»

Gil rejects the conventional dichotomy between individual and societal causation of social problems, He claims that it only »distorts the multidimensional reality of 
human phenomena». Therefore, he introduces a system of 'causal levels' or 'causal dimensions' (ibid., 349-354).

The most fundamental causal level consists of society's basic social philosophy. Gil argues strongly for egalitarian and co-operative value premises (ibid., 350-351):

». . . In a society organized on non-egalitarian and competitive principles, full and free development for all children is simply impossible, as, by definition, there must always be losers in such societies, whose chances to realize their inherent potential will be severely limited. Hence, significant developmental deficits for large segments of the population or high levels of socially structured and sanctioned abuse of children are endemic in such societies.»

Another dimension includes the »social policies that maintain different levels of rights for children from different social and economic backgrounds.» The next one is »a society's attitude towards the use of force as a legitimate means for attaining an end.» Furthermore, he includes a dimension at the interpersonal level in the home and in child care settings which is made up of sintrapsychic conflicts and various forms of psychopathology on the part of perpetrators.»

And finally, there are the striggering contexts». This dimension consists of the specific circumstances which trigger an abusive attack. In general, as Gil states, stress and frustration serve as triggers for parental abusive behavior by causing reduction or loss of self control. But, he continues, it is also obvious, that a higher level of stress will increase the probability of punishment by violence in families in which the physical modes of correction are accepted by the parents (ibid., 352).

As correctly summed up by Freeman $(1979,31-32)$, what Gil is saying - his basic argument, indeed - is that violence against children is normal in our cultures. It is the unacceptable outcome of legitimate child-rearing practices rather than an indication of deviance and psychopathology. The social philosophy in modern societies is based on competitive and non-egalitarian value premises. According to Gil $(1975,350)$, »everyone strives to get ahead of others, considers himself entitled to privileged conditions and positions, and views and treats others as potential means to be used, exploited and dominated in pursuit of his egoistical goals.» The use of force in imbalanced interpersonal relations (e.g., male-female, adult-child) is widely accepted. Similarly, the triggering contexts for parental child abuse are deeply rooted in our society's economic and productive systems. In fact, Gil feels that a complete social revolution is needed to eradicate child abuse.

\section{Sources of stress and frustration}

What are the sources of stress and frustration? Firstly, there is, according to Gil, poverty and its correlates, whigh density in over-crowded, dilapidated, inadequately served neighborhoods; large numbers of children, especially in one-parent mainly female-headed households; and the absence of child care alternatives» (ibid., 352). And secondly, there are the alienating circumstances in most workplaces. Gil refers to studies which show the deepening trend of work alienation among constantly 
growing segments of the working population. This may lead to an increasing incidence of alcoholism, drug addiction, psychosocial problems - and conflicts within the family.

It is obvious that poverty and its correlates cannot explain the frequently reported occurrence of child abuse in homes of economic adequacy or affluence. To solve this problem a more generally operating factor is needed. Hence, the variable of the alienating quality of working circumstances was introduced by Gil. The justification of this solution, however, seems not to be very obvious. Without trying to reject the existence of poverty and the large extent of alienation in our societies, the question arises whether it is not possible to refer to even more general sources of stress in order to gain understanding of child abuse as a social problem.

Gil's conception of the prevalence of egoism and competition between individual people as a fundamental characteristic of human relations in Western societies comes very close to that of Arséne Dumont, the late French demographer. Dumont stated that it is man's universal desire to advance in social rank and to better his economic position (Dumont 1890). ${ }^{5}$ This urge called 'capillarité sociale' by Dumont, is an important motivating force of social and economic progress.

Thus, Gil and Dumont do not share the same attitude towards the similar observations they have made. However, there is an effect of this social capillarity which Dumont finds undesirable, that is, the decline of the birth rate. In trying to climb towards more wealth and power, ambitious individuals avoid and rid themselves of anything which could hamper them. A large family in this struggle is a burden. Hence, the prediction follows: the increase of social mobility - and as a consequence - the increase in economic and social inequality will cause a declining tendency in fertility.

To conclude, what is purported by Dumont is that there are such strong pressures on parents which, being deeply rooted in the economic and social structures, induce low fertility among them. In terms of 'stress and frustration', family limitation is an adaptation to the stresses caused by the urge for a better economic position.

There is another consequence of importance. The pressures which cause the avoidance of additional pregnancies after the first or second birth are present during the whole fertile period of the family life cycle. There may be problems even with one or two children: the risk of losing a job due to pregnancy, the loss of the wife's salary, the lack of child care services, the increase of interrelated economic, emotional and sexual problems, etc. The intensity of stress caused by children may be lower with one child or two, but it is always there.

\section{An economic fertility theory by Easterlin}

In order to make these ideas clear, let us consider another fertility theory which is more recent. Richard A. Easterlin (1975) has presented a model which he refers to as an economic framework for fertility analysis. It consists of four variables:

\footnotetext{
s See also E. P. Hutchinson (1967).
} 
(i) the demand for children $\left(\mathrm{C}_{\mathrm{d}}\right)$, i.e., sthe number of surviving children parents would want if fertility regulation were costless»);

(ii) the potential output of children $\left(\mathrm{C}_{\mathrm{n}}\right)$, i.e., »the number of surviving children parents would have if they did not deliberately limit fertilityn; and

(iii) the motivation for fertility regulation, which is defined as equal to $C_{n}-C_{d}$;

(iv) the costs of fertility regulation, »including both subjective (psychic) costs and objective costs, the time and money required to learn about and use specific techniques».

It is assumed by Easterlin that the demand for children is determined by income, prices, and tastes among families. According to the conventional economic theory of household choice, it depends on the household's continuous efforts to balance its "subjective tastes for goods and children against externally determined constraints of price and income in a way that maximizes its satisfaction» (Easterlin 1975, 42). Furthermore, there is a quality aspect involved in the parental family planning. 'Child quality' is seen by Easterlin as an additional good which parents are able to create by investing more inputs of time, care, schooling and goods. An increase in income may change subjective preferences relating to child quality »leading, for example, to greater emphasis by parents on the quality of the children at the expense of number of children».

The potential output of children depends on the level of natural fertility and mortality in children and adolescents. The determinants of natural fertility are frequency of intercourse, level of fecundity as affected by involuntary causes and fetal mortality from involuntary causes. It is assumed that the potential output of children is positively correlated with the development of nutrition and health among the members of society until a certain point of development is achieved.

In cases where the potential output of children exceeds their demand, parents are in a choice situation of two alternatives: either they will have unwanted children or they must begin to limit their fertility. The decision is seen by Easterlin as the result of comparison between the costs of fertility and the motivation to regulate fertility. Thus, motivation is a necessary condition for fertility limitation, but it is not a sufficient condition.

Let us consider now how these variables are used by Easterlin in order to gain understanding of fertility trends in the course of modernization. Figures 1,2 and 3 illustrate alternative ways in which the motivation to regulate fertility and the actual number of surviving children may emerge during the socio-economic development of society.

The potential output of children $\left(\mathrm{C}_{\mathrm{n}}\right)$ is assumed to increase from a low level in the early stages of development until, at a certain maximum point, it becomes unaffected by further developments. Simultaneously, the improving socio-economic circumstances in society cause a declining tendency in the demand for children $\left(C_{d}\right)$. The motivation to limit fertility emerges at point $\mathrm{m}$.

In Figure 1, it is assumed that the costs of fertility limitation are totally prohibitive. The problem of unwanted children emerges and the actual number of surviving 


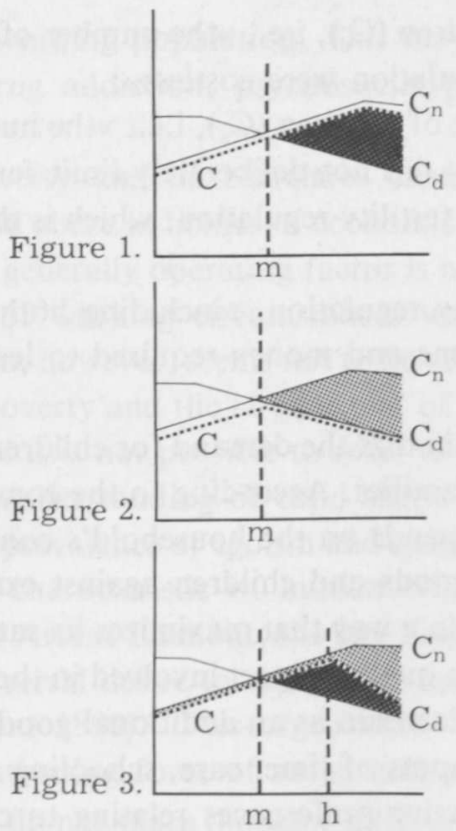

Hypothetical trends in fertility variables associated with economic and social modernization. $\mathrm{C}_{\mathrm{n}}$ is the number of surviving children parents would have in an unregulated fertility regime, $C_{d}$ is the desired number of surviving children in a perfect contraceptive society, and $\mathrm{C}$ is the actual number of surviving children (the definitions refer to the total number over the reproductive career of the »representative» household).

children $(C)$ is equal to the potential output. Figure 2 shows the alternative of the perfect contraceptive society where subjective and market costs of fertility regulation are zero. The actual number of children $(C)$ follows the $C_{d}$ curve.

A more realistic situation is shown in Figure 3. The costs of fertility regulation are high enough to exceed the motivation to limit fertility, up to a certain point (h). It is assumed that there is a point $(\mathrm{h})$ at which costs caused by unwanted pregnancies will be considered by parents as too high in comparison with the costs of fertility regulation. As the movement to the right continues, the degree of voluntary fertility regulation will increase.

Once again, it seems possible to analyze and interpret results of fertility theory research in terms of 'stress and frustration'. Obviously there are two aspects of importance then:

(i) Firstly, it is reasonable to assume that the unwanted pregnancies cause stress and frustration in the family. As shown in Figure 1, this source of stress increases rapidly in the course of modernization if the costs of fertility regulation are prohibitive. In the alternative (see Figure 3 ) which was considered as corresponding more closely to the real world situation, a certain amount of unwanted pregnancies is also continuously present. In fact, many surveys on contraceptive populations in indust- 
rialized countries show that the proportion of unwanted and unplanned pregnancies is still surprisingly high. For example, the percentage of unwanted pregnancies was in the United States, in 1965-1970, 15 per cent, with a total of 44 per cent for unplanned births (Ryder \& Westoff 1972). In Finland, in 1971, only 51 per cent of respondents said that their last pregnancy was wanted. The frequency of contraceptive errors was about 17 per cent (Ritamies \& Visuri 1975). In Britain, in 1973, 35 per cent of respondents with three and 55 per cent of respondents with four children considered their last pregnancy which led to a live birth, as regrettable (Simons 1978).

(ii) Secondly, although it would be possible to decrease the stress caused by unwanted children by using contraceptives more effectively, it would not reduce the pressures which make parents consider fertility limitation as a necessity. Thus, the increasing stress among parents which was attributed to the alternative in Figure 1, is actually present in the alternative of Figure 3 as well. The main difference between these two situations is that in the latter one, the stress is divided into two components: one due to unwanted pregnancies and the other to economic and psychic costs of fertility limitation. And all the time parents are subject to the socio-economic pressures which make the small family advantageous or inevitable.

\section{Some applications}

Furthermore, the framework outlined above seems to provide opportunities for better understanding of some unusual characteristics of child abusive behavior (see Gelles 1973, 615-618).

Firstly, the evidence lends support to the claims that intra-family violence occurs more often in the lower class or the working class. Bearing Figure 3 in mind, one could now state that the costs of fertility regulation, absolutely or relatively, are probably larger for poor families than for the more affluent. Therefore, the stresses caused by unwanted children or by the risk of unwanted pregnancies may be intensified among parents of lower classes.

Secondly, given that men are usually more aggressive than women, it is surprising that females are often highly represented or overrepresented in cases of child abuse (see Gelles 1973). One explanation for this, provided by the Easterlinian framework, is that the stress defined above has a natural tendency to be focused on the mother. It is she who is subject to the risks of becoming pregnant or losing her job. It is she who immediatly bears the responsibilities of rearing the child. Consistently with this it has also been found that a child who is the product of an unwanted pregnancy often is highly vulnerable to abuse from the frustrated mother (ibid.).

Thirdly, the studies lead also to the assumption that children from three months to three years of age are particularly vulnerable to parental abuse (see ibid.). This may be due to the fact that the vulnerability of a child to physical damage is greater the younger she is. But it is reasonable to suppose, as well, that the stresses she causes her parents - especially her mother - are very intensive during the first 
years of her lifetime before any effective adaptative methods to release them has been developed by her parents. It is the new-born baby who creates economic problems and interferes wiht professional, occupational or other plans of the parents.

\section{Conclusion}

The discussion in this paper leads to the conclusion that there is an association between the simultaneous appearance of child abuse and low fertility in the welfare societies. It is theoretically possible to understand fertility behavior which tends to reduce the number of children close to the minimum and parental child abuse by referring to common sources of stress and frustration in the family.

These sources are deeply rooted in the economic and social structures of our society. Via a multidimensional causal structure they contribute to the manifestation of child abuse on many levels - from interpersonal relations between family members to the level of social policies which allow the existence of psychosocial and environmental hazards to children. According to this reasoning, the eradication of child abuse is not possible without fundamental changes in the position of families as related to the structures of economic base and production.

\section{References}

Abrams, Natalie: Problems in Defining Child Abuse and Neglect. In Onora O'Neill \& William Ruddick (Eds.): Having Children - Philosophical and Legal Reflections on Parenthood, pp. 156-164. Oxford University Press, New York 1979.

Calot, Gerard \& Hecht, Jacqueline: The Control of Fertility Trends. In Population Decline in Europe, pp. 178-197. Council of Europe, London 1978.

Densen-Gerber, Judianne \& Hutchinson, S. F.: Medical-legal and Societal Problems Involving Children. In Selwyn M. Smith (Ed.): The Maltreatment of Children, pp. 317-350. MTP, London 1978.

Dumont, Arsène: Dépopulation et civilisation, étude demographique. Paris 1980.

Easterlin, Richard A.: An Economic Framework for Fertility Analysis. Studies in Family Planning 6, $54-63,1975$.

Freeman, M. D. A.: Violence in the Home. Saxon Housen, London 1979.

Gelles, R.: Child Abuse as Psychopathology - A Sociological Critique and Reformulation. Americal Journal of Orthopsychiatry 43, 611-632, 1973.

Gil, D.: Unraveling Child Abuse. American Journal of Orthopsychiatry 45, 346-361, 1975.

Henry, D. R.: The Psychological Aspects of Child Abuse. In Selwyn M. Smith (Ed.): The Maltreatment of Children, pp. 205-219. MTP, London 1978.

Hutchinson, E. P.: The Population Debate. Houghton Mifflin, Boston 1967.

Jacobs, J.: Child Abuse, Neglect and Deprivation and the Family. In Selwyn M. Smith (Ed.): Maltreatment of Children, pp. 245-316. MTP, London 1978.

Kempe, C. Henry: The Battered Child Syndrome. Journal of the American Medical Association 181, $17-24,1962$.

Kempe, Ruth S. \& Kempe, C. Henry: Child Abuse. Fontana/Open Books, London 1978.

Korpilahti, Marja: Lasten pahoinpitelyt ja niiden käsittely Suomessa ja Ruotsissa. Oikeuspoliittisen tutkimuslaitoksen julkaisuja 46, 1981.

Light, R.: Abused and Neglected Children in America: A Study of Alternative Policies. Harvard Educational Review 43, 560-567, 1973. 
Lystad, Mary Hanemann: Violence at Home - A Review of the Literature. American Journal of Orthopsychiatry $45,328-345,1975$.

Newson, J. \& Newson. E.: Patterns of Infant Care in an Urban Community. Penguin, London 1965.

Oliver, J. E.: The Epidemiology of Child Abuse. In Slewyn M. Smith (Ed.): The Maltreatment of Children, pp. 95-115. MTP, London 1978.

Ritamies, Marketta \& Visuri, Elina: Suomalaisten perhekoko - sattuma vai suunnitelma? Väestöntutkimuslaitoksen julkaisuja, Sarja D, No. 1. Helsinki 1975.

Ryder, N. B. \& Westoff, C. F.: Wanted and Unwanted Fertility in US, 1965-1970. In C. F. Westoff \& R. J. Parke (Eds.): Demographic Aspects of Population Growth. Commission Research Reports I. Governmental Printing Office, U.S. 1972.

Simons, John: Illusions about Attitudes. In Population Decline in Europe, pp. 197-215. Council of Europe, London 1978.

Spinetta, J. \& Rigler, D.: The Child-Abusing Parent: A Psychological Review. Psychological Bulletin 77, 296-357, 1972.

Statistical Yearbook of Finland 1981. Central Statistical Office of Finland, Helsinki 1982.

The History of Childhood. Ed. by. Lloyd de Mause. The Psychohistory Press, New York 1974. U.N.: The Determinants and Consequences of Population Trends. Vol. I, 1973.

Vuoristo, Pekka: Ruumiillinen kuritus periytyy. Suomen Kuvalehti 3, 16-17, 1979.

WHO: The Child and Adolescent in Society. WHO Regional Office for Europe. Euro Reports and Studies 3. Copenhagen 1979. 